\title{
Percutaneous absorption of progesterone in postmenopausal women treated with transdermal estrogen
}

\author{
Kenneth A. Burry, MD, Phillip E. Patton, MD, and Kent Hermsmeyer, PhD \\ Portland, Oregon
}

OBJECTIVE: The objective of this study was to evaluate the serum levels of progesterone resulting from the application of a progesterone cream to the skin.

STUDY DESIGN: Six postmenopausal women were evaluated at a university clinic over a 4-week period.

RESULTS: Transdermal estradiol $0.05 \mathrm{mg}$ was applied 2 days before the first application of progesterone (30 $\mathrm{mg} / \mathrm{d}$ ) and was continued throughout the study. Patches were changed twice a week. Progesterone cream was applied once a day for 2 weeks. On day 15 and for the next 2 weeks, the progesterone cream was applied twice daily $(60 \mathrm{mg} / \mathrm{d})$. Serum $17 \beta$-estradiol and progesterone were measured at 9 different times over a 24-hour period on day 1 and at weekly intervals for the 4-week duration of the study. Serum 17 $\beta$-estradiol concentrations varied among women, with mean concentrations of 40 to $64 \mathrm{pg} / \mathrm{mL}$ observed. Consistency in $17 \beta$-estradiol concentrations was found within individual persons throughout the study. Serum progesterone concentrations also varied among women, with mean concentrations ranging from 1.6 to $3.3 \mathrm{ng} / \mathrm{mL}$. After 2 weeks of percutaneous dosing, progesterone concentrations were sustained for at least 8 hours and were consistent within a given person. An appropriate increase in progesterone concentration occurred after 4 weeks compared with 2 weeks of application. Individually, a 0.53 correlation, significant at $P<.0001$, was seen between the absorption of $17 \beta$-estradiol and progesterone.

CONCLUSION: Significant increases in serum concentrations of progesterone were observed in all of the women studied. The percutaneous absorption of progesterone correlates strongly with the absorption of transdermal $17 \beta$-estradiol. There is variance in absorption of progesterone just as with $17 \beta$-estradiol, and the 2 measures are closely correlated. The percutaneous application of progesterone cream appears to be a safe and effective route of administration. (Am J Obstet Gynecol 1999;180:1504-11.)

Key words: Hormones, progesterone, transdermal

The use of exogenous estrogen by postmenopausal women is associated with many health benefits including protection from osteoporosis and cardiovascular disease. One known risk of estrogen use is endometrial cancer; therefore women with a uterus should take a progestin in addition to estrogen to prevent this risk. Unfortunately, available progestins have side effects such as weight gain and depression, which may result in a decrease in compliance to treatment. Many women are currently using the natural progestin, progesterone, to treat menopausal symptoms either alone or in conjunction with estrogen. Limited evidence exists that progesterone is safe or efficacious in the various doses and routes of administration being used by women.

The use of micronized progesterone is effective in in-

From the Departments of Obstetrics and Gynecology and Medicine, Oregon Health Sciences University.

Sponsored by Astraea Inc.

Presented at the Sixty-fifth Annual Meeting of the Pacific Coast Obsetrical and Gynecological Society, British Columbia, Canada, September 16-20, 1998.

Reprints not available from the authors.

Copyright () 1999 by Mosby, Inc.

$0002-9378 / 99 \$ 8.00+0 \quad 6 / 6 / 97414$ ducing amenorrhea during hormone replacement therapy. Various routes of administration of micronized progesterone have been shown to be protective to the proliferative changes of the endometrium caused by estrogen. Oral, transvaginal, and nasal administrations of this hormone have been shown to be effective and well tolerated. ${ }^{1-5}$

Because progesterone is naturally an ovarian hormone, the route of administration most closely analogous would be parenteral. The lipid solubility of progesterone predisposes toward a percutaneous method of administration. Progesterone is available in a variety of creams or gels without a prescription. These are applied to the skin. Although some products sold as progesterone cream do not contain progesterone but instead are based on wild yam extracts, which are not metabolized to progesterone by women, other creams contain pure United States Pharmacopeia progesterone prepared by chemical synthesis in doses ranging from 0.17 to $30 \mathrm{mg} / \mathrm{g}$. This study selected Pro-Gest, a commercially available product with $30 \mathrm{mg} / \mathrm{g}$ progesterone. Evidence is lacking, pro or con, that these products increase plasma levels sufficiently to improve menopausal symp- 


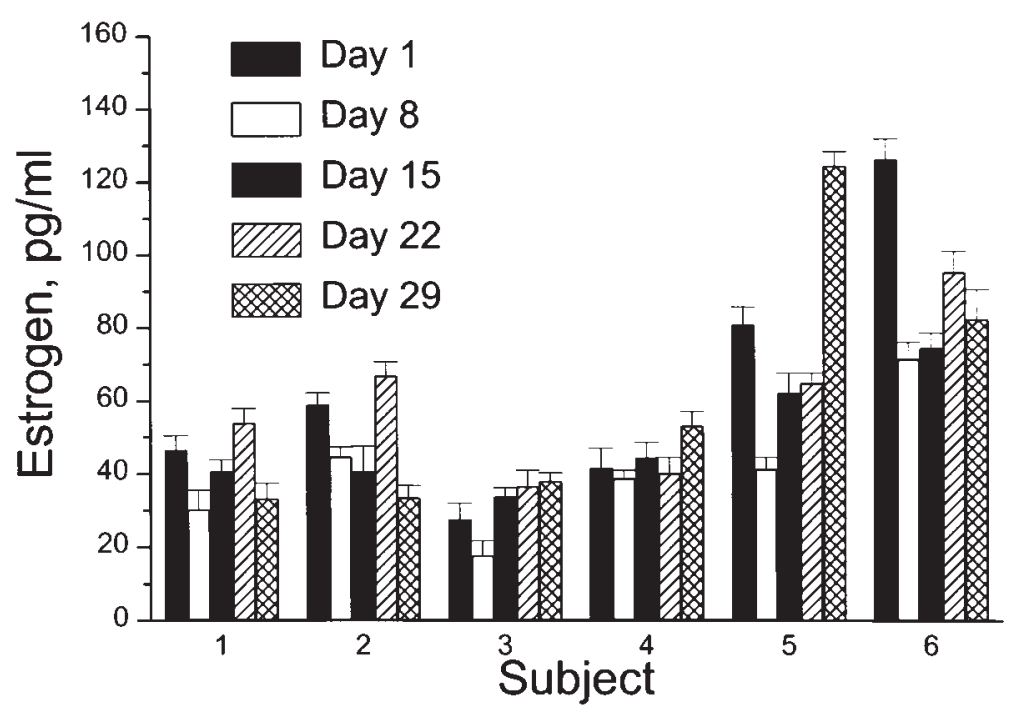

Fig 1. Individual averages of $17 \beta$-estradiol were measured on each of 5 study days. $17 \beta$-Estradiol levels were relatively constant over 4-week duration of study, but there was large (maximum of $\times 3$ ) variation among persons, especially after 2 days of application. Values represent mean \pm SEM.

toms and, most significantly, to protect the endometrium from the proliferative effects of estrogen. This article represents a step toward determining percutaneous absorption that translates into serum progesterone levels as measured in a group of nonfasting postmenopausal women with estrogen replacement. Under these realistic conditions we studied the blood levels of progesterone achieved with a progesterone skin cream.

\section{Material and methods}

Six normal postmenopausal women consented to be studied per an institutional review board-approved protocol over a 30-day study period. One woman, aged 40 years, had premature ovarian failure, and the other 5 women ranged in age from 50 to 65 years and had $>1$ year of amenorrhea. The body mass index of these women was $<40$. All women were treated with $17 \beta$-estradiol administered transdermally at a dose of $0.05 \mathrm{mg}$ (Vivelle) changed twice a week for the 4 weeks of the study. Progesterone cream, Pro-Gest, was first applied to the arms, legs, or chest beginning 2 days after the first estrogen patch was applied on the lower torso. The dose of progesterone in this cream is $30 \mathrm{mg} / \mathrm{g}$ in a base containing vitamin $\mathrm{E}$ and aloe vera. During the first 2 weeks of the study the participants applied exactly premeasured amounts of $1 \mathrm{~g}$ (containing $30 \mathrm{mg}$ progesterone) of the cream once a day. During the last 2 weeks of the study the women applied the same amount of cream twice a day (60 mg/d progesterone).

Serum was obtained at 8 time points (hours 1, 2, 3, 4, $6,8,12$, and 24) on each of days 1, 8, 15, 22, and 29 for the purpose of measuring estradiol and progesterone. Hormone assays were done by immunoassay with the
Immulite system. ${ }^{6}$ Standard curves were controlled for the concentration of hormones observed in this study. Assays of the progesterone concentrations $<1 \mathrm{ng} / \mathrm{mL}$ on the Immulite system were obtained by radioimmunoassay (DSL-3400 kits; Diagnostic Systems Laboratories, Webster, Tex). Statistical analysis was performed by analysis of variance and Newman-Keuls tests with $P<.05$ used as the level of statistical significance. For correlation analysis linear regression was used without a predetermined level of significance. Computer software for statistical analysis was Origin 5, Microcal.

\section{Results}

Serum estradiol concentrations (as the average of 8 samples during each of the first and 4 subsequent weekly measurement days) varied from a minimum of 18 $\mathrm{pg} / \mathrm{mL}$ to a maximum reported $124 \mathrm{pg} / \mathrm{mL}$ (Fig 1). A significant difference was seen in serum concentrations of estrogen, even though all the women received the same dose. However, there was consistency in estrogen concentrations in a given person throughout the study. The combined mean estradiol concentration for all women ranged from 41 to $64 \mathrm{pg} / \mathrm{mL}$ for the 5 weekly analyses (Fig 2).

Serum progesterone concentrations as averages of 8 time points at each of the weekly intervals varied among women between mean concentrations ranging from 1.0 $\mathrm{ng} / \mathrm{mL}$ to $3.3 \mathrm{ng} / \mathrm{mL}$ (Fig 3). Pooled group averages for all 6 women for the 5 study days ranged from serum progesterone concentrations of $1.6 \mathrm{ng} / \mathrm{mL}$ at the second measurement to $2.3 \mathrm{ng} / \mathrm{mL}$ at the fourth measurement (Fig 4). Considered individually, progesterone concentrations increased to a peak value at variable times 


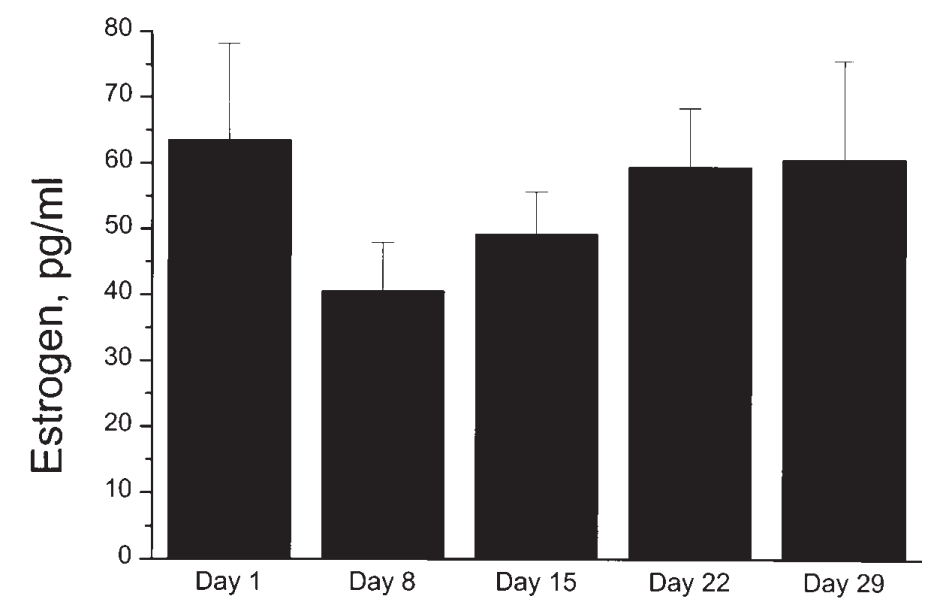

Fig 2. Group means of all subjects show that estrogen levels were relatively constant during study except for initial spike at day 1 , which probably represents reintroduction of estrogen. Values represent mean \pm SEM.

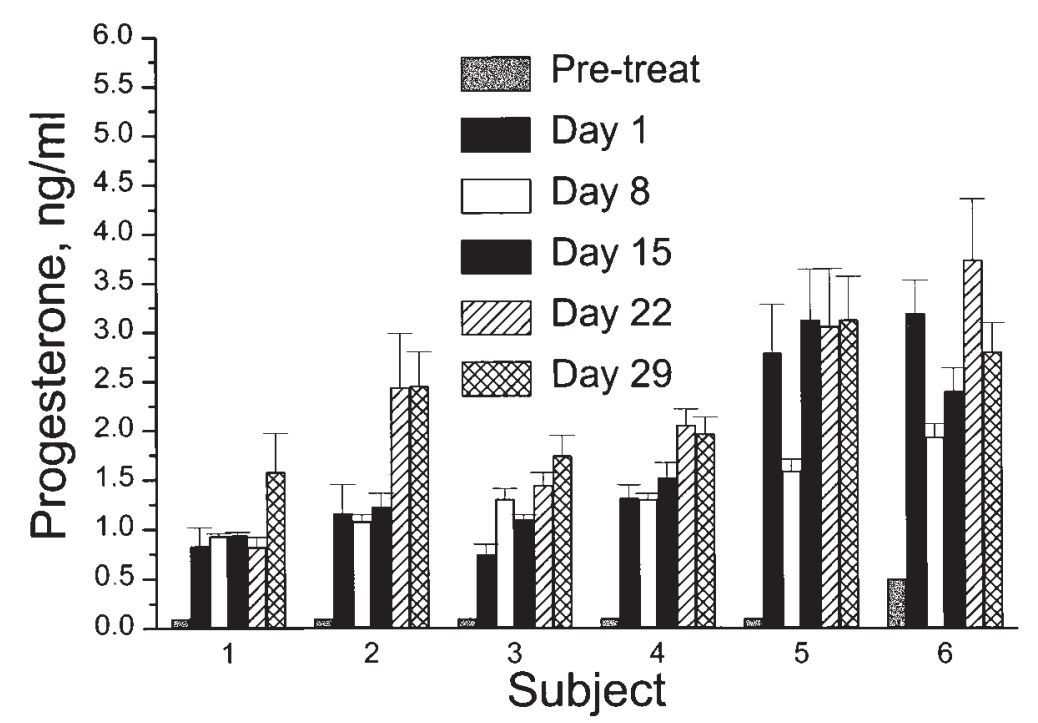

Fig 3. Individual averages of progesterone were measured before treatment and on each of 5 study days. Progesterone levels varied almost 4-fold among women, with highest and lowest levels appearing consistently in same subjects. Clear increase occurred in progesterone concentration with doubling of dose by twice-a-day application during last 2 weeks of study. Values represent mean \pm SEM.

among women for several hours after percutaneous application and were sustained at approximately $1 \mathrm{ng} / \mathrm{mL}$ for at least 8 hours in 5 of the 6 subjects at the beginning (Fig 5) and in all 6 subjects by the end of the 4-week treatment protocol (Fig 6). The peak value occurred as late as 12 hours after application after 2 weeks of twicedaily application, which followed 2 weeks of once-per-day dosing (Fig 6). There were increases in progesterone concentrations appropriate for the dose when the oncea-day application of the cream was compared with the twice-a-day application (Figs 3 and 4).

Every measurement of progesterone levels was significantly greater than at baseline $(P<.05)$. The baseline progesterone value of $0.17 \mathrm{ng} / \mathrm{mL}$ represents the minimum detectable level in subjects 1 through 5 and thus is likely to be an overestimate. This undetectable level increased immediately on application (day 1) and was maintained to every time point. Day 15 was also different from day 8 , reflecting the increased dose beginning that day. Day 1 and day 8 progesterone levels were each significantly different from day 22 or day 29 levels.

The individual consistency in progesterone concentrations (Fig 3) was similar to that observed with estradiol concentrations (Fig 1). Estradiol levels were more variable among women but were more consistent over time, as expected from the continuous release patch system. A strong correlation was seen between the absorption of estradiol and progesterone. Women with the highest serum concentration of estrogen had the highest serum concentration of progesterone and vice versa (Fig 7). 


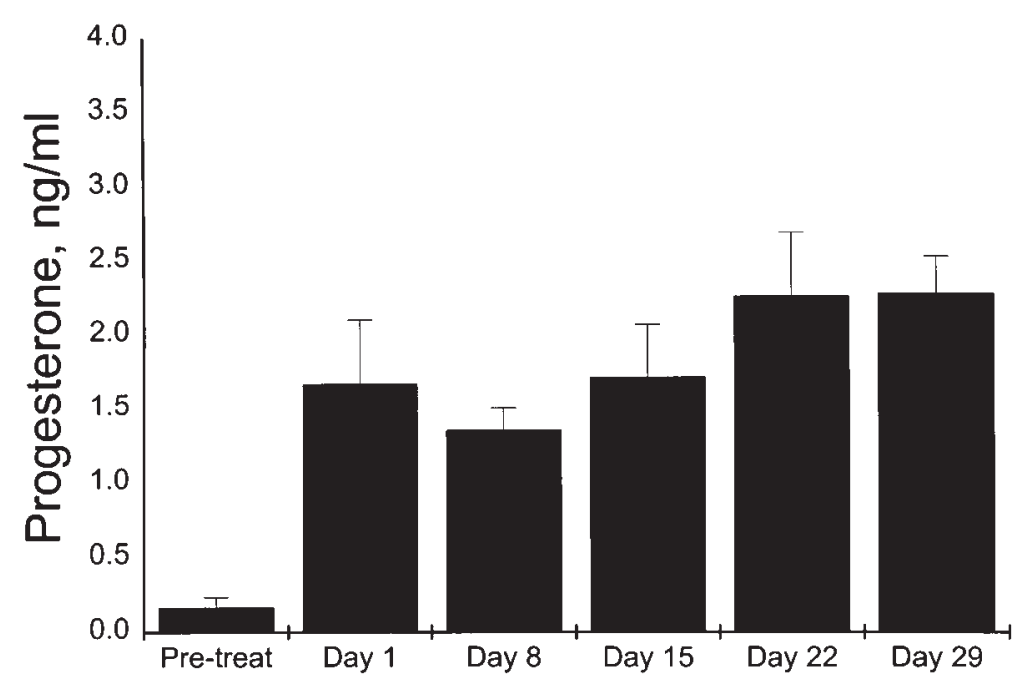

Fig 4. Group means of all subjects show that progesterone levels increased markedly at beginning of treatment and increased on day 15 with introduction of second application each day. Baseline values are likely to have been even lower than shown, which is lower detection limit. Values represent mean \pm SEM.

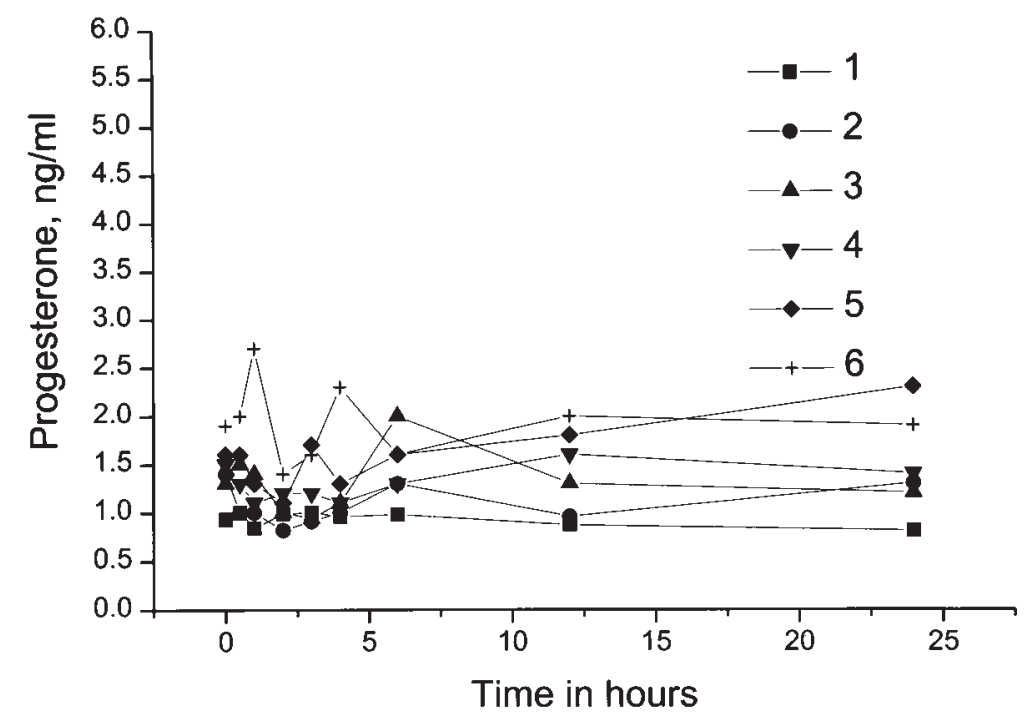

Fig 5. Time points for progesterone levels in blood serum by immunoassay are plotted individually for all 6 women at end of first week of study. Approximately 2-fold variation was seen in both peak and sustained levels, which occurred at times between 0.5 and 6 hours among women. Differences in time of maximum progesterone levels and of rapid peak concentrations may be at least partly explained by interactions of food intake with blood levels.

The linear correlation of progesterone concentration to estradiol concentration was $r=0.53$, with a significance level of $P<.0001$.

\section{Comment}

Oral micronized progesterone has been used successfully to protect the endometrium from the proliferative effects of estrogen. Gillet et $\mathrm{al}^{2}$ reported that $100 \mathrm{mg} \mathrm{mi-}$ cronized progesterone given 25 days of the month protected the endometrium from proliferation and resulted in induction of amenorrhea in $>90 \%$ of women. ${ }^{2}$ The Postmenopausal Estrogen/Progestin Interventions
(PEPI) trial compared micronized progesterone with medroxyprogesterone acetate and found micronized progesterone to have an effect on the endometrium as efficacious as that of medroxyprogesterone acetate while having a less negative impact on high-density lipoprotein cholesterol. ${ }^{7}$ Recent evidence has caused concern about the cardiovascular consequences of the use of medroxyprogesterone acetate and has raised the question of selecting and optimizing progestin doses and route of administration. 8,9

Various nonoral routes of administration of progesterone have been used in treating postmenopausal 


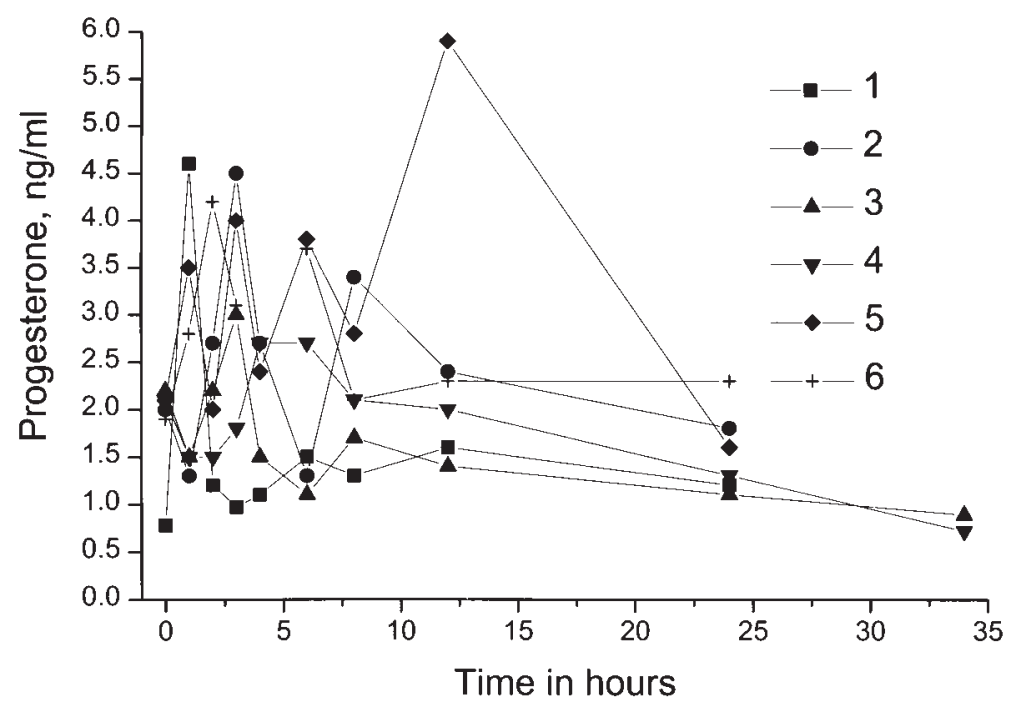

Fig 6. All time points for progesterone levels in blood serum after 2 weeks of twice-daily percutaneous application of progesterone skin cream also showed approximately 2-fold differences between persons in progesterone levels and variability between 1 and 12 hours in time to peak concentration. Concentrations increased progressively during study, and serum levels became more consistent during the day. Additional progesterone measurements at 34 hours in subjects 3 and 4 indicate that return to baseline levels would be expected at approximately 36 hours.

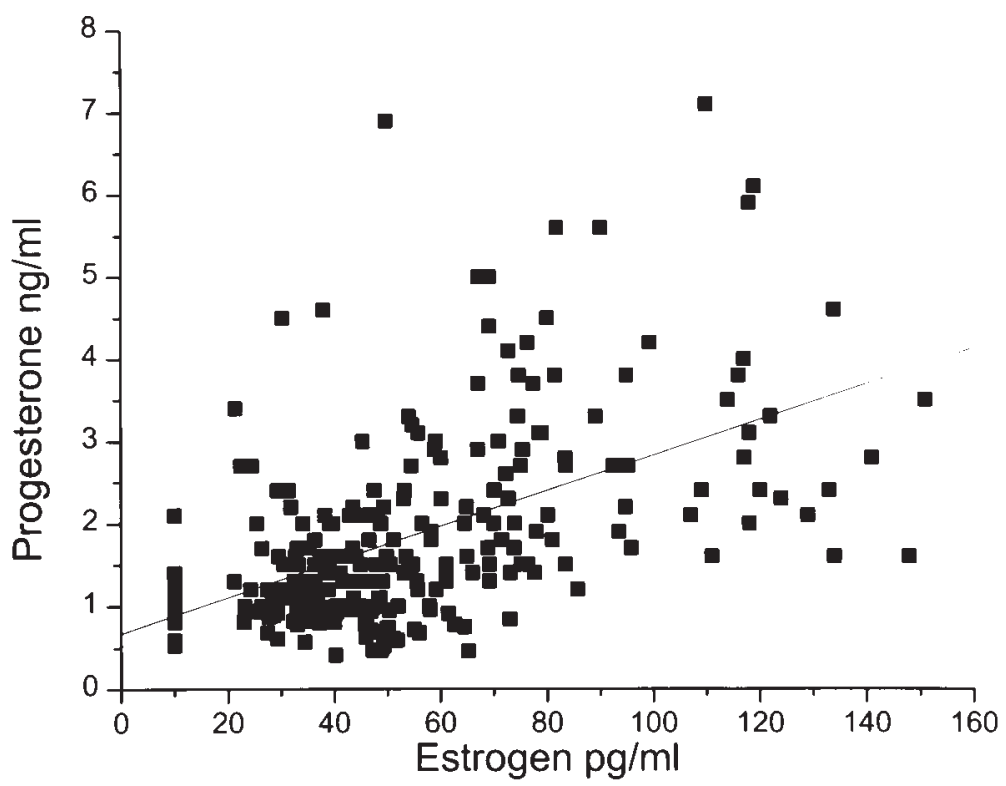

Fig 7. Strong positive linear correlation was seen for this group between serum progesterone and 17ß-estradiol concentrations, suggesting similar percutaneous absorption of both corticosteroids; $r=0.53, P<.0001, \mathrm{n}=264$.

women receiving estrogen replacement. Intramuscular and vaginal progesterone produced similar serum levels of progesterone and effects on the endometrium. Miles et $\mathrm{al}^{10}$ reported that agonadal women undergoing embryo donation achieved a secretory endometrium with vaginal micronized progesterone. The delivery of progesterone to the uterus was enhanced by the vaginal route compared with a standard intramuscular regimen. Affinito et al $^{11}$ treated women with benign endometrial hyperplasia effectively with a vaginal cream consisting of
$100 \mathrm{mg}$ natural micronized progesterone in a polyethylene glycol base used from days 10 to 25 of the cycle. Other investigators have also reported success in achieving luteal serum progesterone concentrations and secretory changes in the endometrium in response to vaginal application of progesterone. Even studies with low serum concentrations of progesterone have shown beneficial effects on the endometrium, suggesting a direct transit to the uterus for a "first uterine pass effect."

Fanchin et $\mathrm{al}^{4}$ reported that 45 to $90 \mathrm{mg}$ vaginal prog- 
esterone gel induced normal secretory transformation of the endometrium corresponding with plasma progesterone levels of 3.4 to $3.6 \mathrm{ng} / \mathrm{mL}$. Similar levels of $>3$ $\mathrm{ng} / \mathrm{mL}$ could be achieved by application of the progesterone skin cream used in this study. Another route of administration available is nasal spray. Five to 7 days of treatment with a nasal spray containing $34 \mathrm{mg}$ progesterone resulted in secretory endometrial changes in postmenopausal women treated with estrogen. ${ }^{5}$ Thus it seems possible that the absorption of progesterone across mucus membranes, vaginal mucosa, and the skin may result in an increased bioavailable level of the hormone, therefore providing an endometrial effect with lower serum levels of progesterone.

Only limited data are available on the use of percutaneous progesterone. A role for both the stratum corneum and the hair follicle has been proposed to influence the absorption rate. ${ }^{12}$ Progesterone gel has been found to be absorbed rapidly and dose-dependently, with luteal phase concentrations achieved. In that study at 2to 3-hour time points, a 100-mg dose resulted in peak levels of 5.9 to $8.0 \mathrm{ng} / \mathrm{mL}$ progesterone, although a lower 30-mg dose failed to raise progesterone to luteal levels. ${ }^{13}$

Many women are currently using progesterone creams sold without prescription to manage menopausal symptoms. Some of these women are using estrogen together with these creams and thus without any other progestin. Pharmacokinetics of progesterone are quite complex, and thus the serum levels are not obvious and may be counterintuitive. ${ }^{14}$ No evidence exists as to whether percutaneous progesterone creams are protective against endometrial cancer. This study reports that percutaneous absorption of a progesterone cream occurred in 6 postmenopausal women treated with estrogen. This study was designed to measure the blood serum levels of estrogen and progesterone during normal activities, allowing variations introduced by normal eating times, even though blood levels from percutaneous application may vary as a function of food intake. ${ }^{15}$ In this respect this study reflects realistic variations in hormone levels.

The doses of progesterone used in this study were significantly less than those used in the gel study. The progesterone concentration in the product used in our study was $30 \mathrm{mg} / \mathrm{g}$. At this concentration percutaneous application of a measured dose of $1 \mathrm{~g}$ daily and then $1 \mathrm{~g}$ twice a day resulted in clearly significant increases in blood levels of progesterone. However, we expect that the doses of progesterone in other creams on the market that use only $0.17 \mathrm{mg} / \mathrm{g}(5 \mathrm{mg} / \mathrm{oz})$ would clearly not be adequate to achieve levels thought to be necessary for hormone replacement, because even the $30 \mathrm{mg}$ of progesterone daily in $1 \mathrm{~g}$ of this cream produced only 1 - to $2-\mathrm{ng} / \mathrm{mL}$ increases (to below luteal levels) in some of the women. Percutaneous delivery of $30 \mathrm{mg} / \mathrm{d}$ perhaps represents the lower end of the dosing range that should be considered in a long-term study on the endometrial responses of postmenopausal women treated with estrogen replacement. This point should be tested.

This study reports serum levels of estradiol and progesterone, both applied through the skin. The percutaneous absorption of estradiol was variable among women but remained consistent individually. Women choosing the transdermal route for estrogen replacement should be evaluated for adequate dosing, because estradiol levels $<30 \mathrm{pg} / \mathrm{mL}$ may be less protective against osteoporosis and cardiovascular disease than the intended levels, $>40 \mathrm{pg} / \mathrm{mL}$. Progesterone levels were also variable among the subjects, but, as with estradiol, the serum levels were individually consistent. It is interesting that women had similar absorption efficiency with both estradiol and progesterone, as shown by the Fig 7 correlation. Women who had higher serum levels of estradiol also had higher serum levels of progesterone. The rate-limiting factor for skin absorption of ovarian corticosteroids may be related to the individual transport and metabolism differences in the skin and its appendages. ${ }^{12,} 14$

This study has demonstrated that progesterone is absorbed through the skin and that luteal levels of serum progesterone can be achieved. It appears that the progesterone cream used in this study may be a reasonable delivery system for elevating progesterone in postmenopausal women and thus for managing part or possibly all symptoms of ovarian corticosteroid deficiency. Yet to be defined is the optimum dose required for endometrial protection from the proliferative effects of estrogen in women receiving long-term hormone replacement therapy.

\section{REFERENCES}

1. Bolaji II, Tallon DF, O'Dwyer E, Fottrell PF. Assessment of bioavailability of oral micronized progesterone using a salivary progesterone enzyme immunoassay. Gynecol Endocrinol 1993;7:101-10.

2. Gillet JY, Andre G, Faguer B, Erny R, Buvat-Herbaut M, Domin $\mathrm{MA}$, et al. Induction of amenorrhea during hormone replacement therapy: optimal micronized progesterone dose. Maturitas 1994;19:103-15.

3. Cicinelli E, Borraccino V, Petruzzi D, Mazzotta N, Cerundolo ML, Schonauer LM. Pharmacokinetics and endometrial effects of the vaginal administration of micronized progesterone in an oil-based solution to postmenopausal women. Fertil Steril 1996;6:860-2.

4. Fanchin R, De Ziegler D, Bergeron C, Righini C, Torrisi C, Frydman R. Transvaginal administration of progesterone. Obstet Gynecol 1997;90:396-401.

5. Cicinelli E, Petruzzi D, Scorcia P, Resta L. Effects of progesterione administered by nasal spray on the human postmenopausal endometrium. Maturitas 1993;18:65-72.

6. Dancoine F, Couplet G, Buvat J, Guittard C, Marcolin G, Fourlinnie JC. Analytical and clinical evaluation of the Immulite estradiol assay in serum from patients undergoing in vitro fertilization: estradiol increase in mature follicles. Clin Chem 1997;43:1165-71

7. Miller VT, the PEPI Writing Group. Effects of estrogen or estrogen/progestin regimens on heart disease risk factors in postmenopausal women, the Postmenopausal Estrogen/Progestin Interventions (PEPI) trial. JAMA 1995;273:199-208.

8. Miyagawa K, Rösch J, Stanczyk F, Hermsmeyer K. Medroxyprogesterone interferes with ovarian steroid protection against coronary vasospasm. Nat Med 1997a;3:324-7. 
9. Miyagawa K, Vidgoff J, Hermsmeyer $\mathrm{K}$. $\mathrm{Ca}^{2+}$ release mechanism of primate reactivity based coronary vasospasm. Am J Physiol 1997;272 Suppl:H2645-54.

10. Miles RA, Paulson RJ, Lobo RA, Press MF, Dahmoush L, Sauer MV. Pharmacokinetics and endometrial tissue levels of progesterone after administration by intramuscular and vaginal routes: a comparative study. Fertil Steril 1994;62:485-90.

11. Affinito P, Di Carlo C, Di Mauro P, Napolitano V, Nappi C: Endometrial hyperplasia: efficacy of a new treatment with a vaginal cream containing natural micronized progesterone. Maturitas 1994;20:191-8.

12. Hueber F, Schaefer H, Wepierre J. Role of transepidermal and transfollicular routes in percutaneous absorption of steroids: in vitro studies on human skin. Skin Pharmacol 1994;7:237-44.

13. Bello SM, Mezrow G, Shoupe D, Winer SA, Stanczyk FZ. Administration of progesterone by use of a percutaneous gel in postmenopausal women [abstract O-10]. In: Proceedings of the Forty-fifth Annual Meeting of the Pacific Coast Fertility Society; 1997 Apr 10-13; Indian Wells, California. Indian Wells: The Society; 1997.

14. Kowalski WB, Chatterton RT Jr, Kazer RR, Severini TA. Disappearance and unexpected reappearance of progesterone in the circulation of the monkey: novel hormone kinetics. J Physiol (Lond) 1996;493:877-84.

15. Nakajima ST, Gibson M. The effect of a meal on circulating steady-state progesterone levels. J Clin Endocrinol Metab $1989 ; 69: 917-9$

Editors' note: This manuscript was revised after these discussions were presented.

\section{Discussion}

Dr William C. Weiderman, Eureka, California. I found the article by Burry et al very interesting and timely. Today, more information is available via more modalities than ever before. Television, print media, and of course, the Internet provide our patients with vast amounts of information. Unfortunately, particularly in the case of the Internet, very little of this information undergoes any type of formal peer review process. It is becoming more and more common to find myself facing patients with pages of information downloaded from obscure Internet websites about various medications and treatment options. Not only is most of this information unreviewed and unsubstantiated, it is often anecdotal at best and untrue at worst. I find it common now to search for literature on subjects not covered in my training, subjects including acupuncture, aroma therapy, and of course, herbal therapy, where the Food and Drug Administration has currently chosen to place progesterone creams.

I thus read this article with great interest, for in the past 5 years I have had 3 postmenopausal patients referred to me because of postmenopausal bleeding while receiving estrogen replacement therapy and self-prescribed progesterone cream. All 3 were using different creams of varying concentrations applied in inconsistent amounts, and all 3 had no progesterone effect on endometrial biopsy.

Literature searches to date find very few articles dealing with transdermal progesterone. This article represents a good initial investigation into the efficacy of transdermal progesterone. The authors studied 6 postmenopausal women for a 5 -week period. Each woman used a transdermal $17 \beta$-estradiol 0.5 -mg patch continuously. Progesterone cream at a concentration of $30 \mathrm{mg} / \mathrm{g}$ was self-applied once daily for 2 weeks and twice daily for 2 weeks. Serum estradiol and progesterone were measured 8 times per day on days 1, 8, 15, 22, and 29. Results showed significant increases in serum progesterone levels in all women. Percutaneous absorption of estradiol and progesterone demonstrated similar individual variations.

I would like to know whether the site of application of the cream was specified to the patients or left to their discretion. Krause et $\mathrm{al}^{1}$ demonstrated significantly higher absorption levels when comparing progesterone ointment application to the breast with that to the abdomen or thigh. Hence, the site of application would appear to be important for absorption.

Franchin et al, ${ }^{2}$ in their study, had serum progesterone levels similar to those of your study with the application of 45 to $90 \mathrm{mg}$ progesterone gel intravaginally. These serum levels were sufficient to induce normal secretory change in the endometrium. They postulated that a "first uterine pass" induced secretory transformation with progesterone levels significantly less than normal luteal concentrations. Did you do any endometrial biopsies during or after your treatment phase to assess the endometrial response?

I look forward to continued studies to confirm the optimum physiologic dose requirements and related frequency, duration, and site of use of transdermal progesterone. In addition, development of a patch delivery system, similar to transdermal estrogen, would aid in ease of use and in patient compliance.

\section{REFERENCES}

1. Krause W, Wichman U, Horn W. Resorption of progesterone through intact skin of the breast in comparison with other body regions. Geburtshilfe Frauenheilkd 1987;47:562-4.

2. Fanchin R, DeZiegler D, Bergeron C, Righini C, Torrisi C, Frydman R. Transvaginal administration of progesterone. Obstet Gynecol 1997;90:396-401

Dr James C. Caillouette, Pasadena, California. Will you please comment on the data suggesting a greater absorption of estradiol from the estrogen patch if applied to the buttocks compared with application to the abdomen?

Dr Melanie M. Plaut, Vancouver, Washington. How do the serum progesterone levels one sees with percutaneous administration compare to those with oral micronized progesterone in 200- or 300-mg doses?

Dr Jack R. Lamey, Seattle, Washington. Are the serum levels of progesterone that are reached similar when administration is by each of the different routes: transdermal, oral, intramuscular, and vaginal? Second, you had mentioned that yam progesterone derivatives were not absorbed. What was the source of the "natural progesterone" in this cream? Third, can you make a secondary comment regarding the efficacy of "natural estrogens"?

Dr Thomas Holbert, Medford, Oregon. To sort of 
amplify one of the questions before, not only about the serum levels of micronized progesterone but also about what serum levels you would get with Provera, I think, in general, the big question is going to be whether transdermal progesterone is adequate to prevent endometrial cancer as is believed to be the case with the standard Provera dosages? My second question is, what would you tell patients who are using the host of transdermal medications other than Progest as far as the efficacy or safety of those medications?

Dr Martin L. Schwartz, Portland, Oregon. I believe that the authors are reporting data on an unregulated pharmacologic preparation. This being the case, before you began this scientific endeavor, what evidence did you have that this company's product did not vary significantly from batch-to-batch?

Dr BurRy (Closing). We wanted to have women use this product per the manufacturer's recommendation. Most women apply this product to the torso or the extremities. We quantified the amount by the use of a precise applicator. Most women will actually apply $>1 \mathrm{~g}$ of this product when used without supervision.

In answer to Dr Caillouette's question, it is true that hair appendages do increase the absorption of transdermal products such as progesterone. Different sites of application may have a difference in absorption because of these hair appendages, and that may be why there is a difference between abdominal absorption of transdermal estrogen versus the buttocks, where there may be more hair follicles.

We did not do endometrial biopsies on these patients because this was a 4 -week pharmacokinetic study. The next study that we do will obviously include endometrial biopsies and other endometrial assessments, because it is going to be an endometrial safety issue.

To answer Dr Plaut's question, one problem with oral micronized progesterone is that much of it is converted immediately to metabolites that actually interfere with progesterone assays. You really have to do gas chromatography and a mass spectrographic evaluation to make sure you are measuring progesterone. The delivery to the uterus, or progesterone bioavailability, can be accomplished through the oral route, through the vaginal route, obviously through the intramuscular route, and probably through transdermal routes. The doses required for transdermal progesterone protection of the uterus need to be evaluated. It appears that the dose of oral micronized estrogen is at least $200 \mathrm{mg} / \mathrm{d}$ for the last 12 days of the month, and daily doses of $100 \mathrm{mg}$ probably block proliferation of the endometrium in most women.

We really do not know how the serum level of progesterone relates to the effect we want on the uterus, in answer to Dr Lamey's question. Low serum levels of progesterone achieved through the vaginal route provide endometrial protection. Maybe it is the first-pass effect; however, there is also a nasal spray that is being used in Europe that delivers $34 \mathrm{mg}$ progesterone, which also provides endometrial protection. You cannot explain firstpass effect to the uterus by applying it in the nose. Small amounts of progesterone through mucus membranes do give good tissue levels, even though serum levels may be low. The source of progesterone and many of the estrogens is actually from the wild yam.

Dr Holbert asked whether this is adequate to prevent endometrial carcinoma. Those are data yet to be determined. We are hopeful that we will be able to come back in a year or so and give you some data from our studies to maybe clarify that answer. What do I tell patients about these other products? If the product is like most of the products on the market, they have $5 \mathrm{mg}$ progesterone per ounce, which is an ineffective dose. You could bathe in it and not get enough absorption of progesterone to have a tissue effect or a serum effect. The wild yam creams have no bioavailable progesterone. I warn women that they do not have endometrial protection with most of these products.

In answer to Dr Schwartz's question, ProGest is really not an unregulated product, because it is filed with the Food and Drug Administration and it is approved as a cosmetic. The dose of $450 \mathrm{mg} / \mathrm{oz}$ is tightly controlled in this product. 